\title{
aniki
}

Revista Portuguesa da Imagem em Movimento

Portuguese Journal of the Moving Image

\section{Cinephon: Sobre como o cinema sonoro impulsionou a fabricação de projetores cinematográficos no Brasil Rafael de Luna Freire ${ }^{1}$}

\begin{abstract}
Introdução
Este artigo tem o objetivo de resgatar e analisar a trajetória de uma das mais importantes e menos estudadas indústrias ligadas ao cinema no Brasil. O provável motivo para seu desconhecimento pelos historiadores se deve ao fato de não estarmos tratando de empresas e profissionais dedicados à produção de filmes brasileiros, aquilo que geralmente se entende por "indústria cinematográfica" nos estudos sobre cinema no Brasil. Estamos nos referindo, na verdade, ao conjunto de companhias que atuaram no mercado da exibição cinematográfica no país. Nosso interesse recai sobre as empresas voltadas ao fornecimento de equipamentos utilizados pelos exibidores e, dentre elas, às empresas brasileiras de montagem, fabricação e comercialização de equipamentos de projeção cinematográfica sonora.
\end{abstract}

Neste artigo, analisaremos mais especificamente a história da primeira marca de projetores sonoros nacionais lançada no país, a Cinephon, fabricada inicialmente pela J. Barros \& Cia, do Rio de Janeiro, a partir de 1930. Podemos desde já destacar que foi a chegada e posterior popularização do filme sonoro no final da década de 1920 que, além de provocar inúmeras mudanças no mercado exibidor brasileiro, alavancou o desenvolvimento dessa indústria no país. Cinephon foi uma das marcas surgidas em meio às reviravoltas provocadas pela chegada da tecnologia do cinema sonoro ao Brasil.

Evidentemente, trata-se de uma abordagem da história do cinema no Brasil incomum em diversos aspectos. Por um lado, neste artigo o texto fílmico é descentrado (falaremos pouco sobre filmes, em si), pois buscamos analisar o cinema pelo viés de sua circulação e consumo, em sintonia com o que que vem sendo recentemente chamado de New Cinema History (Maltby 2011, 3). Por outro lado, o foco na história da exibição e recepção se dá especialmente sob o prisma de uma história tecnológica do cinema, mas que não se

${ }^{1}$ Universidade Federal Fluminense, Instituto de Arte e Comunicação Social, Departamento de Cinema e Vídeo, 24210-590, Niterói, Brasil. 
dedica às grandes invenções ou aos principais inventores. Uma abordagem metodológica pautada em três estágios - invenção, inovação e difusão - foi sugerida como um promissora abordagem historiográfica para a análise da introdução de um novo produto ou processo tecnológico no clássico Film History: Theory and Practice, um dos marcos da hoje consagrada New Film History ${ }^{2}$ (Allen e Gomery 1985). No caso da Cinephon, estamos falando do estágio da difusão, inclusive internacional, da tecnologia do cinema sonoro, "quando a tecnologia começa a ganhar amplo uso numa indústria" (Allen e Gomery 1985, p. 115). Esse estágio envolve adaptações que, em nosso caso, incluem imitações e simplificações de uma tecnologia importada para atender às demandas dos exibidores brasileiros.

Além disso, esse estudo de uma empresa fabricante de projetores sonoros no Brasil aproxima-se da perspectiva do estudioso sobre o som no cinema, Rick Altman, quando este descarta uma história tecnológica meramente evolucionista e teleológica. Em sua visão, para entender a tecnologia do cinema, um dos pontos é "começar analisando sua recepção - a forma pelo qual a [tecnologia] é construída pelos seus usuários”, investigando, portanto, a construção social da tecnologia (Altman 2004, 16). É o que pretendemos aqui ao analisar os equipamentos Cinephon no contexto do mercado exibidor brasileiro nos anos 1930.

Por fim, nos avizinhamos da premissa de Laura Isabel Serna que, em seu estudo sobre a cultura cinematográfica mexicana, "complica a equação entre cinema nacional e produção nacional" (Serna 2014, 217). Em nosso caso, a intenção é apresentar um estudo que possa desafiar a tradicional equivalência entre indústria cinematográfica brasileira e o setor da produção de filmes brasileiros. Como uma pioneira fornecedora de equipamentos para os empresários brasileiros dedicados à exibição, sobretudo, de filmes estrangeiros, defendemos que Cinephon decididamente tem um papel relevante na história do cinema no Brasil. Isso se deve especialmente ao fato de que o Brasil, apesar de reconhecidos esforços e talentos, era principalmente um mercado exibidor e consumidor de filmes importados no período que estamos abordando. Foi mirando nesse mercado que a empresa surgiu.

\footnotetext{
${ }^{2}$ Chamamos de New Film History a história revisionista do cinema que emerge no final dos anos 1970, na Europa e nos Estados Unidos, reformulando, por exemplo, a visão sobre o que então era chamado de "cinema primitivo", realizado até o início do século XX. Unindo estudiosos e arquivos de filmes, ela teria como marco simbólico inicial a conferência da Federação Internacional de Arquivos de Filmes (FIAF), em Brighton, em 1978.
} 


\section{Os projetores no início do cinema no Brasil}

No Brasil, nos primórdios da era do chamado "filme silencioso", o cinema era uma atração e uma tecnologia essencialmente importadas. Como destacou Tom Gunning (1990, 64-65), nas primeiras projeções comerciais o público "ia às exibições para ver demonstrações de máquinas (a nova maravilha tecnológica), e não para assistir filmes. O que era anunciado era o Cinematógrafo, o Biógrafo, o Vitascope”. No Brasil, é importante frisar, tratavam-se ainda de maravilhosas máquinas importadas, novidades trazidas por viajantes diretamente da Europa e Estados Unidos. E não apenas em termos de promoção as máquinas se sobressaíam aos filmes. Nos primeiros tempos dos exibidores ambulantes e das salas de cinema temporárias no Brasil, a compra de algumas cópias de películas (estrangeiras) representava um investimento financeiro mais alto do que a aquisição do equipamento de projeção em si (igualmente estrangeiro). Num catálogo de 1905, destinado àqueles que desejavam se iniciar no negócio cinematográfico, a empresa importadora Marc Ferrez \& Filhos listava os itens necessários. Dentre eles, "um projetor completo" custava seiscentos mil reis (600\$000), enquanto um lote de filmes somando 300 metros - a quantidade mínima para a realização de pelo menos uma sessão - era mais caro, saindo por $750 \$ 000$ (Condé 2012, 23). Além do mais, o custo do projetor poderia ser amortizado por seu longo tempo de uso, enquanto as cópias invariavelmente se danificavam após algumas dezenas de projeções, possuindo um tempo de vida mais curto.

Inicialmente, os aparelhos para exibição dos filmes eram muito simples, aproveitando, por exemplo, as fontes luminosas das lanternas mágicas. Logo, porém, projetores cinematográficos mais aperfeiçoados passaram a ser utilizados e comercializados. Essa demanda só aumentou com o advento das salas fixas de cinema, por volta de 1907-1908, em diversas cidades do Brasil, que passaram a exigir o uso regular e constante, diário, dos aparelhos. Além disso, surgia a necessidade de aumentar a potência e a qualidade dos projetores (para atender a espaços mais amplos e plateias mais exigentes) e reforçar sua segurança (diante do perigo da película de nitrato de celulose, altamente inflamável). Entretanto, na abertura e manutenção de uma sala de cinema, o projetor continuaria não representando o gasto inicial mais alto do exibidor, tanto diante de despesas regulares - aluguel, compra ou reforma do espaço, gastos com eletricidade e publicidade, pagamento de funcionários (especialmente os músicos) -, quanto de outros investimentos, às vezes mais altos, como a aquisição dos assentos (bancos ou cadeiras) para o público.

Ainda nesses primeiros tempos, as empresas e empresários que adquiriam cópias de filmes no exterior para exploração no mercado brasileiro (por compra direta, depois por contrato de locação) eram chamados de importadores. Muitos desses 
importadores - depois conhecidos como distribuidores - forneciam, além de filmes, equipamentos de projeção. Até meados da década de 1910, o mercado brasileiro era dominado pelos filmes franceses, especialmente da companhia Pathé Frères, e os projetores Pathé também eram os mais populares, sendo a marca utilizada, inclusive, como sinônimo de cinema (cf. Souza J. 2004). A já citada empresa Marc Ferrez \& Filhos, representante brasileira dos filmes da companhia francesa, era uma das maiores vendedoras de equipamentos de projeção, mas não a única.

Um exemplo pode ser citado da talvez mais antiga revista brasileira de cinema preservada - a edição n. ${ }^{0} 23$ da Revista Cinematographica, publicada em agosto de 1913 -, que trazia anúncios do projetor Pathé Frères, "último modelo", "todo montado em aço", ao preço de 400 mil réis (400\$000) - valor $30 \%$ menor do que em 1905. A propaganda destacava que os melhores cinemas do Rio de Janeiro ("Odeon, Pathé, Avenida e Parisiense"3) "só usam os aparelhos da grande usina Pathé Frères, de Paris", comercializados pelo exibidor e importador J. R. Staffa (Imagem 1). A publicação de listagens das mais afamadas salas de cinema que utilizavam a marca de projetor anunciada, como nesse caso, se tornaria uma das mais frequentes estratégias publicitárias dos vendedores de equipamentos.

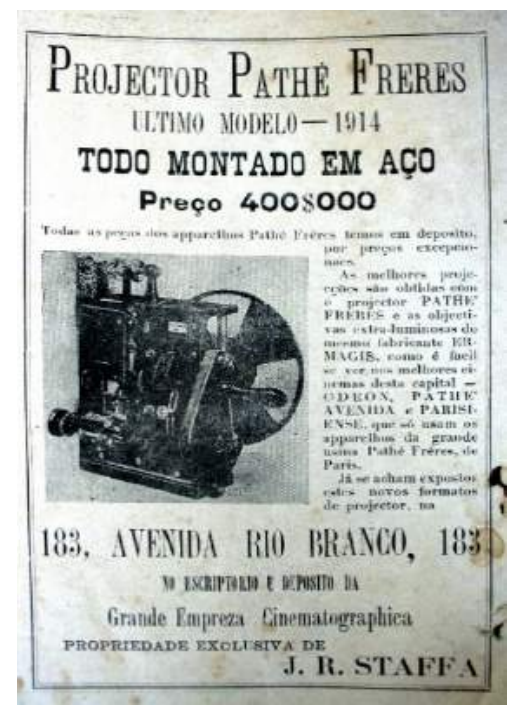

Imagem 1: Anúncio do projetor Pathé. Revista Cinematographica, v.1, n.23, ago. 1913 Domínio Público. (c) Acervo da Cinemateca do MAM-RJ.

A mesma revista, porém, trazia outra propaganda anunciando para setembro de 1913 a chegada ao mercado brasileiro da Power's Cameragraph, “a máquina cinematográfica mais empregada pelos

\footnotetext{
${ }^{3}$ São citadas as salas mais luxuosas da cidade, todas localizadas no endereço nobre da Avenida Central, depois Avenida Rio Branco: Pathé, Avenida e Parisiense, inaugurados em 1907, e Odeon, em 1909 (Gonzaga 1996, 276-281).
} 
exibidores norte-americanos”, sinal do início da concorrência mais intensa aos fabricantes europeus.

De fato, a popularização do cinema norte-americano no Brasil durante a Primeira Guerra Mundial foi acompanhada pela expansão na venda de equipamentos de projeção fabricados nos EUA. A marca que se tornou provavelmente mais conhecida foi a Simplex. Segundo reportagem da revista Cine-Mundial, de fevereiro de 1916, esses projetores chegavam ao mercado brasileiro nesse ano, com a abertura de uma agência no Rio de Janeiro. Não parece coincidência isso ter ocorrido quase simultaneamente à instalação das primeiras agências de distribuição no Brasil dos grandes estúdios de Hollywood: a Universal em 1915, Fox e Paramount, também em 1916.

Ao longo dos anos 1920, o mercado brasileiro foi invadido ainda pelos projetores alemães. A própria Marc Ferrez \& Filhos também passou a comercializar projetores Ernemann-Krupp e Hahn Goerz. A companhia distribuidora Urania Film comercializava outro projetor alemão, o Saxonia V Nitzsche. Revelando a popularização dos equipamentos alemães, um anúncio na revista Cinearte, em 17 de novembro de 1926, de um terceiro importador - John Juergens \& Cia - listava 23 cinemas cariocas e paulistas que possuíam projetores Ernemann em funcionamento. Num outro anúncio da mesma revista, em 26 de janeiro de 1927, essa lista já aparecia ampliada. Dentre os cinemas listados, destacavam-se três palácios de cinema recém-inaugurados no Rio de Janeiro, os cinemas Capitólio, Odeon e Império. Cada uma dessas salas possuía dois aparelhos "Magnifizenz". 4

Aparentemente, os melhores cinemas do Rio de Janeiro, então Capital Federal, se dividiram entre o projetor alemão KruppErneman e o francês Gaumont. Um anúncio da Marc Ferrez \& Filhos, na revista Frou Frou, de janeiro de 1930, dizia que esses tradicionais aparelhos franceses, concorrentes da Pathé, eram "adotados nos principais cinemas do Rio: Pathé Palace, Odeon, Glória, Pathé, Copacabana, Mem de Sá, Méier, Primor, Paris, Botafogo, Parisiense". ${ }^{5}$

$\mathrm{O}$ advento do cinema sonoro traria grandes mudanças a esse cenário, com a necessidade da adaptação do circuito exibidor à nova tecnologia importada. Os primeiros cinemas que instalaram equipamentos de projeção de filmes sonoros em São Paulo (cine Paramount, abril de 1929) e no Rio de Janeiro (Palácio Teatro, junho

\footnotetext{
${ }^{4}$ Os cinemas Capitólio e Império, de 1925, e o Odeon, de 1926, estão entre os primeiros palácios de cinema do Brasil. Construídos na região da Praça Floriano, no Rio de Janeiro, foram responsáveis por fazer com que esse quarteirão viesse a ser conhecido como Cinelândia.

${ }^{5}$ Nesse caso, é preciso relativizar o adjetivo "principais" do anúncio. A lista inclui novos e luxuosos palácios de cinema da Cinelândia, como o Glória, de 1925, e o Pathé Paláce, de 1928, mas outros nomes citados eram de salas de cinema populares e antigas.
} 
de 1929) alcançaram grande sucesso, com seus lançamentos batendo recordes de bilheteria. Em meados de 1929, a importação, transporte e instalação de equipamentos sonoros nos sistemas Vitaphone (som em discos) e Movietone (som ótico) custavam verdadeiras fortunas aos exibidores - de 200 a 500 contos de réis $(200.000 \$ 000$ a $500.000 \$ 00)$ - e somente os grandes empresários do setor tiveram condições de arcar com esse pesado investimento naquele momento (Freire 2012, 7-8). Afinal, tratava-se não apenas da compra de leitores de som, mas de variada aparelhagem (amplificadores, controladores, retificadores, alto-falantes etc.), além de adaptações elétricas e arquitetônicas, troca de peças (como as telas de projeção) e treinamento dos operadores.

Inicialmente, a companhia norte-americana Western Electric tentou estabelecer um monopólio na comercialização de equipamentos sonoros para os exibidores brasileiros, vendendo pacotes completos que incluíam obrigatoriamente projetores novos da marca Simplex e a vinda de engenheiros norte-americanos para acompanhar a instalação. Ainda que a Western Electric tenha realmente equipado os mais luxuosos cinemas do Rio e São Paulo, era impossível que a companhia atendesse à grande maioria dos exibidores brasileiros, formada por pequenos empresários que exploravam salas de cinemas nas periferias das capitais e cidades do interior.

Ainda em 1929, a concorrente Radio Corporation of America (RCA) chegou ao mercado brasileiro, oferecendo equipamentos sonoros Photophone, enquanto outras marcas norte-americanas de menor porte - como Pacent e Mellophone - também passaram a ser vendidas por importadores brasileiros.

Se até então a contrapartida sonora dos filmes exibidos no Brasil - em sua enorme maioria estrangeiros e exclusivamente projetados em equipamentos importados - era sobretudo local, sendo criada e executada por sonoplastas, comentadores, músicos e compositores nacionais, isso mudava com a chegada do Vitaphone e Movietone $^{6}$. A crescente exibição de filmes cantados e falados em idiomas estrangeiros, especialmente o inglês, acompanhada da massiva demissão dos músicos brasileiros das salas de exibição, chegou a gerar protestos de cunho nacionalista, inclusive com projetos (jamais concretizados) de sobretaxação de filmes sonoros estrangeiros (Freire 2014).

Ainda assim, o enorme sucesso inicial dos primeiros filmes musicais hollywoodianos e o interesse dos distribuidores norteamericanos pressionavam os exibidores brasileiros pela atualização das salas à nova tecnologia. Essa situação criou uma demanda por produtos que atendessem às exigências e limites dos exibidores

\footnotetext{
${ }^{6}$ Sobre o acompanhamento musical dos filmes silenciosos no Brasil, ver Carlos Roberto de Souza (2014) e Carlos Eduardo Pereira (2014).
} 
brasileiros, sobretudo os de médio e pequeno porte, cuja situação era ainda mais complicada devido à crise econômica e política que o país atravessava às vésperas do golpe que resultou na chamada Revolução de 1930. Diante das necessidades específicas desses clientes, novas e antigas empresas brasileiras passaram a se dedicar à venda de equipamentos de projeção sonora, oferecendo aos exibidores, a preços mais baixos e com condições mais facilitadas, produtos montados ou fabricados no país. Enquanto a Western Electric tentou impor restrições e exigências aos seus clientes brasileiros, buscando moldar o mercado exibidor ao seu padrão de preço e qualidade, as empresas brasileiras se adaptaram às demandas do mercado nacional, tentando atender às necessidades dos exibidores locais em termos de custo, condições de pagamento, assistência técnica e facilidade das instalações.

Foi nesse contexto que surgiu a primeira empresa brasileira de montagem e fabricação de projetores cinematográficos sonoros.

\section{A pioneira Cinephon}

Farmacêutico de profissão, José Joaquim de Barros tornou-se engenheiro por vocação (Medeiros 1990, 48). Em 1928, criou a empresa J. Barros \& Cia. e a instalou na Rua da Quitanda, 60, $1^{\circ}$ andar, no Rio de Janeiro. A primeira referência aos seus negócios que encontramos foi em anúncio da revista Phonoarte, em 15 de agosto 1929, do "fonógrafo ${ }^{7}$ de ampliação [sic] elétrica" da marca Sonata, fabricado por J. Barros \& Cia., empresa àquela altura localizada na Rua Haddock Lobo, n. $465{ }^{8}$

Entre 1928 e 1929, a indústria fonográfica brasileira ${ }^{9}$ se encontrava em franca expansão graças ao impulso trazido pela nova tecnológica de gravação elétrica de discos. Grandes empresas multinacionais como Victor, Columbia, Brunswick e Parlophon instalaram fábricas e estúdios de gravação no país, enquanto as vendas de discos e de toca-discos aumentaram significativamente. Nesse contexto, os toca-discos elétricos nacionais Sonata não miravam apenas clientes das altas classes, os únicos que possuíam, então, condições financeiras para adquirir esses aparelhos para uso

\footnotetext{
${ }^{7} \mathrm{Na}$ época em que o texto se refere, fonógrafo e gramofone eram palavras rotineiramente utilizadas de forma intercambiável, embora originalmente o fonógrafo se refira ao aparelho para registro e reprodução de som em cilindros e o gramofone, em discos. A rigor, portanto, o Sonata seria um gramofone e não fonógrafo. Para evitar dúvidas, utilizamos no texto, exceto nas citações textuais, a expressão toca-discos - que, no Brasil, posteriormente passou a ter como sinônimo a palavra "vitrola" devido à popularidade dos aparelhos da marca Victor.

${ }^{8}$ Jorge José Vittorio Capellaro $(1989,16)$ indica o número 462.

${ }^{9}$ No Brasil, indústria fonográfica se refere ao conjunto de empresas dedicadas à gravação, edição e distribuição de mídia sonora, independente do suporte.
} 
doméstico. Distribuídos pela tradicional loja de discos Optica Ingleza, um dos anúncios dos toca-discos Sonata especificava o objetivo de venda dos aparelhos para uso comercial e audição coletiva: "aceitamos pedidos para instalações especiais em cinemas, teatros, salões e ao ar livre" (Phonoarte, 30 ago. 1929). Um terceiro anúncio novamente indicava a variedade de possíveis usos: "para a casa, o clube, o ar livre, o cinema, etc." (Anuário Cinearte, dez. 1929).

É preciso destacar que exatamente naquele momento segundo semestre de 1929 - os maiores e mais luxuosos cinemas do Rio de Janeiro, localizados na região da Cinelândia e imediações, no centro da cidade, já tinham instalado projetores sonoros importados (todos norte-americanos) e a novidade vinha causando muito sucesso. Consequentemente, havia uma procura dos pequenos exibidores por potentes toca-discos que pudessem oferecer, de forma improvisada e mais barata, algum tipo de sonorização mecânica a filmes originalmente silenciosos, em meio ao sucesso dos novos filmes sonoros. Isto é, alguns pequenos empresários exploravam a estratégia de exibir filmes originalmente silenciosos acompanhados de discos (78rpm), executados em toca-discos, ao invés de sincronizados aos filmes originalmente sonoros pelos discos especiais (33 e 1/3 rpm) do sistema Vitaphone acoplado ao projetor (Freire 2012, 19-21).

$\mathrm{O}$ anúncio do toca-discos Sonata claramente tinha como um de seus possíveis alvos os donos de pequenos e médios cinemas, identificados como potenciais clientes ${ }^{10}$. Empresa atenta à demanda do mercado, não demorou muito para a J. Barros \& Cia. passar da fabricação e venda de toca-discos elétricos para a montagem, fabricação e comercialização de projetores sonoros no sistema de som em discos.

Foi em janeiro de 1930 que a J. Barros \& Cia. concluiu sua primeira instalação para filmes sonoros, tipo Vitaphone, no cine Velo, na Tijuca. Era a inauguração da marca Cinephon de equipamentos cinematográficos de projeção (Cinephon 1930). O Velo era o terceiro cinema carioca aparelhado para o filme sonoro da empresa Exibidores Reunidos, de Luiz Severiano Ribeiro. No ano anterior, o exibidor cearense já tinha convertido suas duas melhores salas no Rio de Janeiro, o cine Ideal, na rua da Carioca, e o cine Atlântico, em Copacabana, mas ambos com a mais cara aparelhagem importada RCA.

Interessada em garantir a rápida conversão do restante de seu circuito para o filme sonoro e atraída pelos custos mais baixos da

\footnotetext{
${ }^{10}$ Na mesma época, em São Paulo, a Casa Murano anunciava seu "theatrophone", da Victor, também um toca-discos "para cinemas", conforme publicidade publicada no jornal Folha da Manhã de 29 de outubro de 1929.
} 
empresa brasileira, a Exibidores Reunidos adquiriu equipamentos da J. Barros \& Cia. para instalação em outros cinemas de sua cadeia exibidora. Além do cine Velo, ainda nos primeiros meses de 1930 Severiano Ribeiro comprou projetores sonoros Cinephon, modelo Vitaphone, para instalação no cine Vila Isabel e no cine Brasil, ambos na região da Tijuca.

Como Severiano Ribeiro, outros exibidores cariocas de médio e pequeno porte também aproveitaram a oportunidade para converteram seus cinemas no primeiro semestre de 1930: a Cinephon modelo Vitaphone foi igualmente instalada no cine Modelo, em Riachuelo, no cine Paraíso, em Bonsucesso, e no cine Méier, conforme reportagem no Correio da Manhã, de 25 de maio de 1930. Até o final do ano, a Cinephon também chegaria ao cine Boulevard, em Vila Isabel, e ao cine Alpha, em Madureira. Através dessas salas de exibição, a atração do cinema sonoro era inaugurada em bairros da Zona Norte e subúrbio da Central do Brasil, ampliando o alcance geográfico do cinema sonoro na então Capital Federal, anteriormente restrito, sobretudo, ao centro da cidade.

Quando a Cinephon foi instalada no cine Ipiranga, em Jacarepaguá - o primeiro cinema sonoro da Zona Oeste do Rio de Janeiro -, a novidade mereceu matéria no jornal Diário Carioca, de 7 de junho de 1930. A reportagem louvava a iniciativa de Elysio Alves Neves, proprietário recente da sala de exibição, que, "num considerável esforço, elevou-a ao nível dos grandes cinemas do centro, colocando aparelhagem completa para o cinema sonoro e dos melhores que existem em funcionamento, isto é, a Cinephon”.

O baixo custo do equipamento nacional, que permitia sua aquisição por proprietários de "cinemas de bairro" - salas que atendiam à vizinhança, mais modestas em relação aos "palácios de cinema" da Cinelândia, no centro do Rio -, foi destacado no catálogo da empresa: “os preços das instalações 'Cinephon' são muito acessíveis, e razoáveis facilidades de pagamento são concedidas aos compradores" (Cinephon, 1930). Em 11 de junho de 1930, a influente revista Cinearte já chamara atenção para a novidade:

Os aparelhos de fabrico nacional, para a reprodução do som e da voz humana, pelo sistema do Vitaphone, estão, cada vez mais, se alastrando pelo Brasil. Tão satisfatórios quanto os da Radio [Corporation of America] ou da Western [Electric], eles tem a vantagem de serem brasileiros e de um preço mais barato. Nesta cidade [Rio de Janeiro], já se encontram instalados vários desses aparelhos, chamados Cinephon e os pedidos de novas instalações aumentam.

A revista destacava ainda que aparelhos Cinephon seriam brevemente instalados em cinemas do Estado de São Paulo, sendo 
que só o exibidor Sebastião Sampaio encomendara instalações para salas de cinco diferentes cidades: Bauru (cine São Paulo), Ribeirão Preto (cine Carlos Gomes), Barretos (cine Santo Antonio), Araraquara (cine São Bento) e Jaú (cine São Joaquim).

Apesar do tom laudatório e publicitário dessas reportagens, havia também resistências - por exemplo, dos distribuidores de filmes estrangeiros - aos equipamentos brasileiros, como relatou a revista Selecta, em 9 de abril de 1930, sem nomear a Cinephon: "Os aparelhos nacionais são mais modestos, mas suprem as necessidades da especialidade. Há, porém, certas marcas de filmes, que recusam películas aos exibidores modestos que possuem esses aparelhos baratos, só porque são brasileiros". Mais do que mera xenofobia, havia uma legítima preocupação dos grandes distribuidores, especialmente das chamadas majors, com a qualidade das exibições sonoras e com a integridade das cópias ao serem projetadas em equipamentos nacionais que não despertavam confiança. Além do mais, os equipamentos sonoros Cinephon provavelmente ainda eram confundidos com meros toca-discos (como fora o caso do próprio Sonata), que muitos exibidores seguiam utilizando para improvisar a exibição de filmes sincronizados.

Considerações mais aprofundadas são dificultadas pela escassez de informações mais precisas, mas é possível, ainda assim, fazer certas suposições ao analisarmos uma fotografia do sistema Vitaphone da Cinephon, num raro catálogo de dezembro de 1930 (Imagem 2). Essa imagem teria sido feita na "cabine de demonstrações" da empresa, mostrando o aparelho "adaptado a um projetor Ernemann II". Uma correia parece ligar o toca-discos especial para discos Vitaphone ao projetor, indicando a possibilidade de se tratar de um improvisado mecanismo de sincronismo mecânico, e não elétrico, no ajuste da velocidade do disco ao filme. De fato, o catálogo explicava, em outra página, que o sistema era formado por, entre outras peças, uma "máquina acoplada mecanicamente ao projetor para acionar o disco em sincronismo com o filme (Vitaphone)" (Cinephon 1930, grifo meu). ${ }^{11}$

\footnotetext{
${ }^{11}$ Em outro artigo, indico que o sistema Sincrocinex, criado e utilizado pelo cineasta Luiz de Barros para projetar aquele que é considerado o primeiro filme sonoro brasileiro, Acabaram-se os otários (1929), também era baseado num sincronismo mecânico entre toca-discos e projetor. No caso do Sincrocinex, porém, tratava-se de um aparelho para discos comuns, de 78rpm, não de $33 \mathrm{e}$ 1/3rpm, como era o da Cinephon (Freire 2013b, 121).
} 


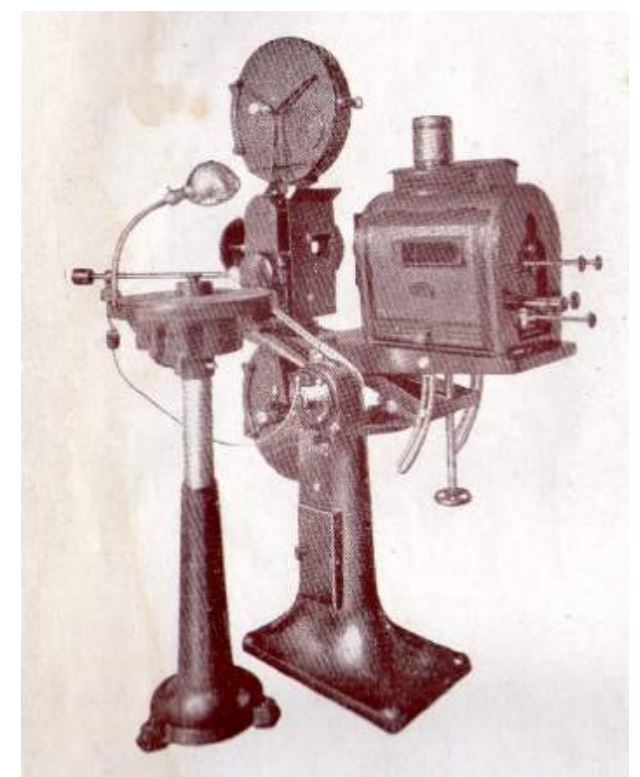

Imagem 2: Fotografia do vitaphone Cinephon adaptado a um projetor alemão Ernemann II (C) Domínio Público (Cinephon 1930).

Em 24 de julho de 1930, uma reportagem em O Jornal estampava a foto de José Joaquim de Barros ao noticiar seu retorno de avião dos Estados Unidos após mais de um mês no exterior. A viagem aérea de seis dias do Rio de Janeiro para Miami pela NYRBA $^{12}$ ainda era uma novidade, e a notícia se justificava também pelo empresário ter aproveitado as escalas no norte do Brasil para fechar negócios. O voo da então Capital Federal para os EUA tinha escala nas seguintes cidades: Campos (RJ), Vitória (ES), Caravelas (BA), Ilhéus (BA), Aracaju (SE), Maceió (AL), Recife (PE), Natal (RN), Fortaleza (CE), Amarração (município renomeado, em 1935, como Luís Correa, PI), São Luiz (MA) e Belém (PA). Os contatos foram bem-sucedidos, pois, ao final do ano, a Cinephon se orgulharia de ter fornecido equipamentos para quatro cinemas nordestinos, em Fortaleza (cine Moderno) e Recife (Royal, São José e Encruzilhada) (Cinephon 1930).

Retratado pela reportagem como modelo de empresário bemsucedido, Barros relatava que, com o advento do cinema sonoro, ele tinha se dedicado ao estudo dos projetores Vitaphone e Movietone. Depois de muitos esforços e tentativas, conseguiu produzir aparelhos no sistema de som em discos, vendidos a preços muito mais acessíveis por serem fabricados no Brasil e usarem materiais nacionais. Entretanto, a viagem para os EUA se justificou pela impossibilidade de fabricar no país o mais complexo sistema de som

\footnotetext{
${ }^{12}$ A empresa aérea NYRBA (acrônimo de New York - Rio de Janeiro - Buenos Aires) iniciou seus voos de hidroavião entre os EUA e a América Latina em 1929. Em janeiro de 1930 foi criada a NYRBA do Brasil. Adquirida pela norte-americana Pan Am, em outubro de 1930 a NYRBA transformou-se em Panair do Brasil, uma das pioneiras e mais importantes companhias áreas brasileiras.
} 
ótico $^{13}$. Barros teria dito ao repórter de $O$ Jornal: "Não podia realizar esse desejo sem ter a representação no Brasil de certas peças indispensáveis cuja fabricação não seria tão compensadora para que fosse iniciada aqui".

De fato, em publicidade publicada no Correio da Manhã, de 25 de maio de 1930, a Cinephon oferecia apenas "instalações para cinema sonoro, sistema Vitaphone (som no disco)”. Porém, já divulgava aceitar encomendas para o "sistema Movietone (som no filme)", anunciando, para breve, a "adição desse sistema" às instalações existentes nos cinemas Vila Isabel (Rio), Modelo (Rio) e Glória (Juiz de Fora).

Após a viagem de Barros aos EUA, a Cinephon passou a oferecer projetores conjugados Vitaphone-Movietone, ou em apenas um dos dois sistemas, conforme o catálogo de produtos do final de 1930. A fotografia abaixo, do mesmo catálogo, mostra o mecanismo do Movietone aberto, instalado na parte inferior do projetor Ernemann II (Imagem 3). À esquerda, é possível ver a "lâmpada excitadora”. Esta produzia um raio de luz que atravessava um sistema de lentes e incidia sobre "a parte do filme onde está gravado o som sobre [sic] a forma de linhas paralelas de intensidade variável ou de uma espécie de traço escuro de altura irregular". Tratavam-se do sistema de som ótico de densidade variável do Movietone, da Western Electric, e o de área variável, Photophone, da R.C.A., ambos reproduzidos pela aparelhagem Cinephon. Após atravessar o filme, a luz chegava ao interior da "válvula foto-elétrica", na parte dianteira (Cinephon 1930).

\footnotetext{
${ }^{13}$ Em 1929, o exibidor Luciano Ferrez já afirmara, em correspondência ao seu irmão Julio, que era possível construir aparelhos Vitaphone no Brasil tão bons quanto os estrangeiros, utilizando peças disponíveis no mercado fornecidas pela Philips, Thomson Houston ou General Electric, para fabricar os sistemas de amplificação e os alto-falantes. A dificuldade, ele frisava, era conseguir fabricar as células foto-elétricas (a "caixa sonora") do sistema de som ótico consagrado pelo Movietone (Freire 2012, 15).
} 


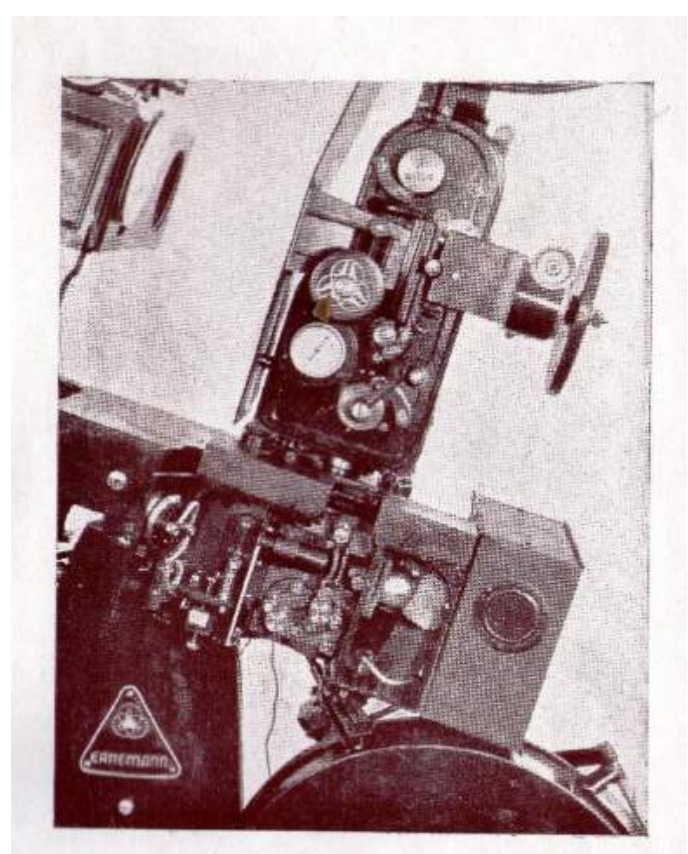

Imagem 3: O mecanismo do Movietone aberto / (C) Domínio Público (Cinephon 1930).

Naquele momento de relativa novidade da tecnologia, ainda era importante esclarecer seus clientes sobre detalhes técnicos do cinema sonoro, assim como expor a complexidade dos novos equipamentos. Dessa forma, o catálogo ilustrado começava por explicar que uma instalação de cinema sonoro era composta de muitas partes. Além do toca-discos para Vitaphone e do leitor fotoelétrico para o Movietone, mostrado nas imagens $2 \mathrm{e} 3$, respetivamente, o sistema incluía ainda:

- Controle para graduação do volume de som na sala de projeção

- Amplificador inicial da válvula foto-elétrica no sistema Movietone e amplificador de voltagem e força para acionar os alto-falantes da tela e monitor da cabine.

- Alto-falantes reprodutores do som na tela.

- Sistema de baterias e retificadores ou motores geradores para fornecimento da necessária corrente contínua aos diversos amplificadores e lâmpadas excitadoras (produtoras do raio de luz no sistema Movietone).

Nas instalações "CINEPHON" todas essas partes são de cuidadosa fabricação reunindo a par do mais fino acabamento, indispensável perfeição mecânica e elétrica (Cinephon 1930).

No final do bem-sucedido primeiro ano de vendas da Cinephon, a empresa possuía representante em São Paulo e se orgulhava de listar 35 cinemas de sete Estados que tinham instalado seus equipamentos (Cinephon 1930). 
Diferentemente da norte-americana Western Electric, que vinha sendo atacada desde o ano anterior por só vender equipamentos sonoros junto com projetores novos da marca Simplex, a Cinephon vendia aparelhagem para ser instalada em qualquer tipo de projetor usado. "Somente é requerido que o projetor se encontre em perfeito estado e seja de boa construção", era ressaltado (Cinephon 1930).

Os preços mais baixos, a facilidade de pagamento e a versatilidade das instalações estimularam as vendas. $O$ argumento nacionalista - especialmente naquele momento de crise econômica que favorecia discursos patrióticos - também era invocado ao se alertar que somente uma pequena parte do capital despendido na compra da Cinephon seria exportado para o exterior, aquele exclusivamente necessário para adquirir matéria prima impossível de ser obtida no Brasil. "Tudo o mais é nacional: a maior parte do material, mão de obra e interesses, pois todos os que trabalham para Cinephon são brasileiros" (Cinephon 1930).

Diante desses argumentos, ao longo de 1931 os projetores Cinephon continuaram sendo instalados em cinemas de bairro cariocas. Em maio, o cine Lapa passou a ter "cinema falado e sonoro, com os mais modernos e perfeitos aparelhos Cinephon vitaphone e movietone", como estampava o programa da sala de exibição. Em outubro, foi a vez do novo cine Catumbi (antigo cine Elegante), da Empresa Luiz Gonçalves Ribeiro. Em dezembro, o último cinema da empresa Vassalo Caruso era convertido para o sonoro, com aparelhagem Cinephon sendo instalada no cine Penha. As notícias repetiam sempre como esses pequenos exibidores "não mediam esforços e sacrifícios" para dotar suas "elegantes salas" da novidade do filme falado e sonoro, revelando, pelo exagero na linguagem, a tentativa de esses cinemas mais modestos adquirirem maior status como espaços de exibição. Para atender aos cada vez mais numerosos clientes, naquele mesmo ano a Cinephon abriu uma sessão de vendas na Rua Buenos Aires, 79, região central da cidade.

Enquanto os cinemas lançadores explicitavam em seus anúncios a instalação de aparelhagem sonora importada da Western Electric ou RCA, apenas em notícias e propagandas de salas do subúrbio do Rio de Janeiro ou de cinemas de cidades do interior encontramos referências aos aparelhos Cinephon. A marca brasileira só era mencionada quando instalada em salas mais modestas em que a inauguração já relativamente tardia do cinema sonoro - mesmo que com equipamentos brasileiros - ainda era, por si só, acontecimento de destaque. Apesar da dificuldade que isso representa para o historiador, é possível afirmar que o número de clientes da empresa continuou crescendo, sobretudo na Região Sudeste. Em 1933, a Cinephon foi incorporada à Companhia Nacional e Importadora, com sede na Rua dos Inválidos, 123. Um anúncio de 31 de dezembro de 1933, no Correio da Manhã, falava em 
"80 instalações feitas e funcionando, algumas com cerca de 4 anos". Além de São Paulo, a empresa carioca já possuía representantes no Nordeste e no Sul do país. José Joaquim de Barros permanecia no cargo de gerente.

Em 15 de abril de 1934, outro anúncio no Correio da Manhã destacava a Cinephon como "a mais antiga marca de aparelhos industrializados no Brasil", trazendo uma impressionante lista de cinemas já equipados com seus equipamentos (Imagem 4). Contavam 26 salas em São Paulo, 21 no Distrito Federal, nove no Estado do Rio e nove em Minas Gerais, quatro em Pernambuco, três no Espírito Santo, duas no Mato Grosso, Ceará e Bahia, e apenas uma no Paraná, em Goiás e Santa Catarina ${ }^{14}$.

A Cinephon também tinha clientes em outros espaços de exibição que não as salas de cinema comerciais. No mesmo anúncio, eram citadas três agências cinematográficas equipadas com Cinephon (as cabines da Universal, First National e United Artists) e duas instalações especiais na marinha (Encouraçado São Paulo e Aviação Naval do Rio de Janeiro), todas no Rio de Janeiro, somando 86 instalações em todo o Brasil. Seis meses depois, conforme anúncio no Cine Magazine, de novembro de 1934, esse número aumentou para 94 instalações, dizia a publicidade da empresa.

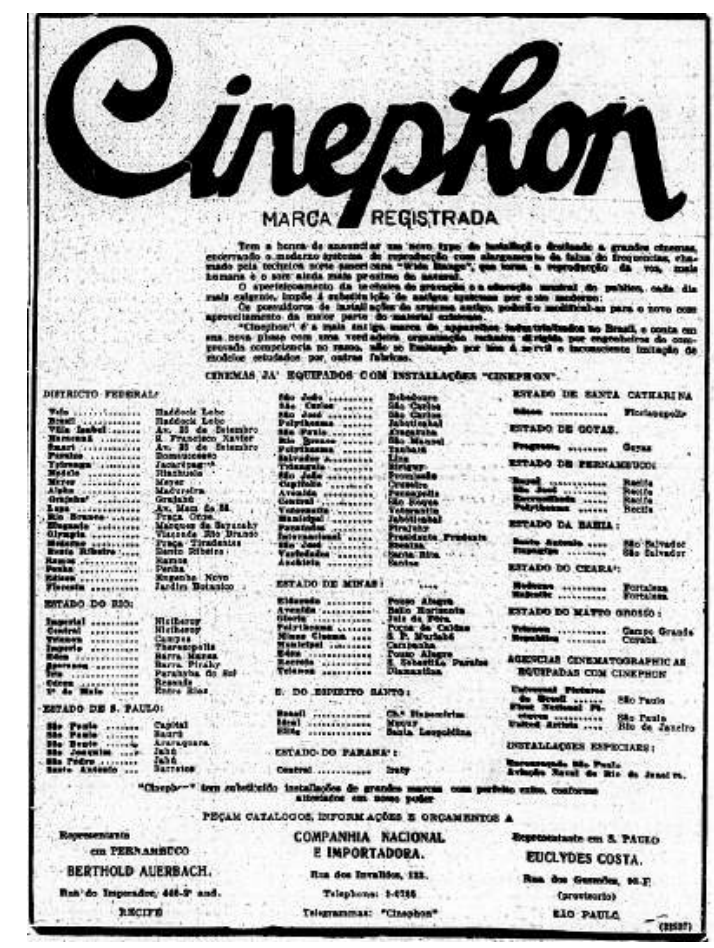

Figura 8: Anúncio Cinephon. Correio da Manhã, 15 abr. 1934, p.12 (C) Domínio Público. Hemeroteca Digital da Biblioteca Nacional.

\footnotetext{
${ }^{14}$ O mercado exibidor da Região Sul do Brasil parece ter sido dominado pelos projetores brasileiros Fonocinex, da Byington \& Cia., a segunda marca nacional de equipamentos de projeção sonora, comercializada a partir de 1931 (Freire 2013c).
} 
Em meados de 1934, a empresa originalmente criada por José Joaquim de Barros foi incorporada por uma nova companhia, a Radio Cinephon Brasileira S.A. (daqui em diante, RCB). Seu nome já revelava a ampliação do escopo de atuação e deixava clara a pretensão de ser uma espécie de RCA nacional. A nova firma se dedicava à "exploração da indústria de aparelhos elétricos, em geral", fabricando também recetores de rádio e estações transmissoras. A RCB foi constituída por Barros em sociedade com o empresário e engenheiro Luiz Corção Braga. Representante no país de companhias norte-americanas, como a Stromberg Carlson, desde meados dos anos 1920, ele era proprietário da tradicional loja Luiz Corção, que comercializava toda a sorte de material telefônico, elétrico e radiofônico. Com escritórios na Rua São Pedro, 33, a loja focava especialmente na venda, recarga e reparo de baterias elétricas para automóveis. Em março de 1934, a empresa Luiz Corção fora reorganizada como Corção, Cardim e Co., tendo como diretores Luiz Corção, Romulo Gomes Cardim e João Alves de Oliveira, que também ingressaram na RCB (Corção, Cardim \& Co. 1934).

Menos de dois meses depois de sua criação, a RCB ampliou seu capital para 300 contos de réis $(300.000 \$ 000)$. A nova diretoria passou a ser formada por Luiz Corção como diretor gerente, por José Joaquim de Barros como diretor de produção, e pelo "técnico de radiotelefonia e radiotelegrafia”, Dr. Carlos Gooda Lacombe, como diretor técnico (Jornal do Brasil, 1 jun. 1934). ${ }^{15}$

Ao longo de 1934, as propagandas da Cinephon na revista corporativa Cine Magazine buscaram equiparar seus produtos aos mais afamados fabricantes estrangeiros, ressaltando seus aparelhos como "os únicos que tem [sic] merecido a preferência dos exibidores de primeira classe para substituir instalações de grandes marcas". Ao mesmo tempo, a empresa oferecia pacotes compatíveis com a realidade de pequenos exibidores, anunciando, por exemplo, "um tipo de instalação 'Movietone', completa, para 600 lugares, ao preço de 6.500\$000, com garantia real de um ano contra defeitos, dada por uma organização técnica e financeiramente poderosa”. O custo para a instalação de Movietone nas salas que já possuíam instalado o sistema Vitaphone era ainda mais baixo, partindo de 3.500\$000. Em meados dos anos 1930, o sistema de som ótico já

15 O engenheiro Carlos Gooda Lacombe (1896-1977), formado pela Escola Politécnica do Rio de Janeiro, foi um dos pioneiros do rádio no Brasil. Em 1927, a revista Rádio Paulista o chamava de o "mais adiantado amador do país". Anos depois, ao ser contratado pela Radio Cinephon Brasileira, Lacombe já era considerado uma verdadeira autoridade em eletrônica. Em 1935, quem ingressaria na RCB seria o engenheiro Gustavo Corção Braga (1896-1978), irmão de Luiz, trabalhando paralelamente à sua carreira de professor universitário. A partir dos anos 1940, Gustavo Corção ganharia prestígio como escritor e liderança católica, sem nunca abandonar a eletrônica. 
tinha se tornado o padrão de exibição de filmes sonoros no Brasil e as salas que só tinham instalado o sistema de som em discos precisavam se equipar com o Movietone (Freire 2013a).

A empresa ainda passou a mirar a clientela não somente dos exibidores, mas também dos produtores cinematográficos brasileiros. Isso se deu especialmente após a regulamentação, em 1934, da obrigatoriedade de exibição de curtas-metragens nacionais junto de todo longa-metragem estrangeiro, estipulada pelo decreto 21.240 de 1932 - medida destinada a estimular a realização de cinejornais, documentários, filmes educativos e cine-atualidades pelos produtores brasileiros. Assim, a Cinephon anunciou, em julho desse ano, na revista Cine Magazine, o início da fabricação e comercialização de aparelhos para gravação de som. Comprovando essa iniciativa, um fragmento recentemente descoberto do documentário As sete maravilhas do Rio de Janeiro (1934), produzido pela Brasil Vita Film, de Carmen Santos, traz uma cartela inicial anunciando que o som do filme fora gravado com equipamentos Cinephon $^{16}$.

É interessante pensar que, provavelmente, no set de filmagem de As sete maravilhas do Rio de Janeiro, o único ou principal equipamento técnico nacional deveria ser o gravador Cinephon, num cenário em que câmeras e negativo, por exemplo, eram invariavelmente importados. A presença da cartela devia se justificar por um possível empréstimo do equipamento para a produção em troca da propaganda.

Apesar da atenção a clientes no meio cinematográfico, com a expansão da radiodifusão comercial no Brasil alimentada pela regulamentação da publicidade nas transmissões radiofônicas através do mesmo decreto 21.240/1932 -, a RCB direcionou sua produção para esse promissor setor. Seus esforços se ampliaram para a fabricação de aparelhos de rádios para os ouvintes e, principalmente, de unidades transmissoras para as emissoras que proliferavam em todo o país. Em 1930, existiam 18 emissoras de rádio em todo o Brasil, cinco delas no Rio de Janeiro. Em 1936, esse número tinha subido para 65 emissoras no país, sendo 15 só na cidade do Rio (Radio Phono, nov. 1930; Carioca, 19 set. 1936). Nesse mesmo ano, a RCB construiu e instalou a unidade transmissora da Rádio Educadora do Brasil, no Rio de Janeiro, e da Rádio Club de Pernambuco, em Recife.

Obviamente, a empresa não desprezou o mercado exibidor cinematográfico, que ainda oferecia boas oportunidades. Em 1935, já havia mais de uma centena de equipamentos Cinephon instalados do

\footnotetext{
${ }^{16}$ Até então considerado perdido, uma cópia incompleta desse filme foi descoberta no acervo do Museu da Imagem e do Som do Rio de Janeiro. Uma nova cópia de projeção em $35 \mathrm{~mm}$ foi feita e exibida pela primeira vez na $9^{\mathrm{a}}$ CineOP - Mostra de Cinema de Ouro Preto, em 2014.
} 
norte ao sul do país, de Sapé, no interior da Paraíba, a Pelotas, no Rio Grande do Sul. Além de aparelhos de projeção de imagem e som, a empresa oferecia em anúncio na Cine Magazine, em junho desse ano, outros "aparelhos mecânico-elétricos" que incrementariam as sessões cinematográficas, como aqueles destinados ao acionamento, à distância, da cortina à frente da tela, ou para o "amortecimento lento da luz nas salas".

Entretanto, com a entrada de novos concorrentes ao longo dos anos 1930 - como a Cinetom, empresa formada no Rio de Janeiro, em 1932, exatamente por dois ex-funcionários da Cinephon -, o mercado de projetores sonoros deixaria de ser o negócio principal da RCB. Na década de 1940, com atuação sobretudo em radiodifusão e telefonia, a empresa seria considerada uma "esplêndida companhia de eletrônica". Os principais produtos de sua linha de fabricação eram: mesas de prova e repetidores de voz para linhas interurbanas, repetidores de programas para ligação de estúdio e estações transmissoras de broadcast e carriers, ou sistemas de "onda portadora" para linhas telefônicas (Medeiros 1990, 48). Posteriormente, ainda no campo das telecomunicações, a empresa também passou a investir em equipamentos como televisores e rádios para automóveis, tendo sido uma das pioneiras no Brasil na fabricação e venda de secretárias eletrônicas. Depois de ser absorvida pela empresa L. F. Braga \& Filhos, a Radio Cinephon Brasileira encerrou suas atividades e teve sua sociedade dissolvida em 1967 (Capellaro 1989, 19).

\section{Conclusão}

Neste artigo, demonstramos como a necessidade de atualização tecnológica em decorrência da chegada e popularização do filme sonoro nos sistemas Vitaphone e Movietone, na passagem para os anos 1930, provocou uma demanda no mercado que fomentou o início da fabricação e montagem de sistemas de projeção sonora por empresas brasileiras. Enquanto as principais empresas exibidoras do país instalaram equipamentos estrangeiros, sobretudo norteamericanos, a maior parte dos proprietários de salas de cinema no Brasil não tinha condições de arcar com os altos custos dessas instalações. Para esses clientes, uma empresa como a pioneira Cinephon desenvolveu produtos com preços e condições de pagamento viáveis, além das facilidades de venda e assistência técnica oferecida por brasileiros e em português. $\mathrm{O}$ argumento nacionalista de valorização da indústria nacional também foi frequentemente invocado, especialmente nos anúncios publicitários da empresa.

Desse modo, ao adotar o viés de uma história tecnológica e econômica do cinema, esse estudo buscou alargar a concepção de 
indústria cinematográfica para além da produção de filmes, para também abarcar, por exemplo, empresas fornecedoras de equipamentos e serviços para o setor da exibição. Demonstramos de que modo uma empresa como a Cinephon, ignorada até hoje pelos historiadores, atuou não somente na fabricação de aparelhos para as salas de cinema, mas também para os produtores cinematográficos. Evidenciamos ainda o aspecto intermidiático dessa história, descrevendo como a Cinephon direcionou seus negócios para a indústria radiofônica e, depois telefônica, de meados dos anos 1930 em diante, sendo que a origem da empresa se situa no amplo desenvolvimento do mercado fonográfico brasileiro no final dos anos 1920. Enquanto historiadores se dividem por seus objetos, quer o disco, o cinema ou o rádio, todas essas mídias se encontram e se cruzam na trajetória da empresa, dos toca-discos Sonata aos transmissores RCB, passando pelos projetores sonoros Cinephon.

\section{BIBLIOGRAFIA}

Allen, Robert C.; Gomery, D. 1985. Film History: Theory and Practice. New York: Alfred A. Knopf.

Altman, Rick. 2004. Silent Film Sound. New York: Columbia University Press.

Capellaro, José J. V. 1989. "História da indústria de equipamentos de telecomunicações no Brasil”. In História da Indústria de telecomunicações no Brasil, editado por Henry British Lins Barros, 13-45. Rio de Janeiro: Associação Brasileira de Telecomunicações.

Cinephon. 1930. Catálogo. Coleção Sylvia Perrone Guimarães, Arquivo Geral da Cidade do Rio de Janeiro, RJ.

Condé, William N. 2012. Marc Ferrez \& Filhos: comércio, distribuição e exibição nos primórdios do cinema brasileiro (1905-1912). Dissertação de mestrado. Rio de Janeiro: Universidade Federal do Rio de Janeiro.

Corção, Cardim \& Co. 1934. Carta para Rádio Sociedade do Rio de Janeiro, 15 mar. http://www.fiocruz.br/radiosociedade. Consultado em: 15 ago. 2015.

Freire, Rafael de L. 2012. "Truste, músicos e vitrolas: a tentativa de monopólio da Western Electric na chegada do cinema sonoro ao Brasil e seus desdobramentos”. Imagofagia: Revista de la Associación Argentina de Estudios de Cine y Audiovisual 5: 1-24. 
——- 2013a. "A conversão para o cinema sonoro no Brasil e o mercado exibidor na década de 1930". Significação: revista de cultura audiovisual 40(40): 32-37

_—_. 2013b. "Acabaram-se os otários: compreendendo o primeiro longa-metragem sonoro". Rebeca 2(3): 104-128

——_. 2013c. "Da geração de eletricidade aos divertimentos elétricos: a trajetória empresarial de Alberto Byington Jr. antes da produção de filmes”. Estudos Históricos 26(51): 113131.

——_. 2014. "O projeto de lei de taxação de filmes falados em língua estrangeira”. In XVII Estudos de cinema e audiovisual Socine: anais de textos completos, editado por Maria Dora Mourão, 563-573. São Paulo: Socine.

Gonzaga, Alice. 1996. Palácios e poeiras: 100 anos de cinemas no Rio de Janeiro. Rio de Janeiro: Record e Funarte.

Gunning, Tom. 1990. "The Cinema of Attractions: Early Film, Its Spectator and the Avant-Garde". In Early Cinema: Space, Frame, Narrative, editado por Thomas Elsaesser. London: BFI.

Maltby, Richard. 2011. "New Cinema Histories". In Explorations in New Cinema History: Approaches and Case Studies, editado por Richard Maltby, Daniel Biltereyst e Philippe Meers. Chichester: Wiley-Blackwell.

Medeiros, Benjamim. 1990. "Miguel de Britto Pereira: Mestre em eletrônica”. AN-EP 99(3).

http://doradioamad.dominiotemporario.com/doc/MIGUEL_ DE_BRITTO_PEREIRA.pdf. Consultado em: 5 mar. 2017.

Pereira, Carlos E. 2014. A música no cinema silencioso no Brasil. Rio de Janeiro: Museu de Arte Moderna, 2014.

Serna, Laura I. 2014. Making Cinelandia: American Films and Mexican Film Culture Before the Golden Age. Durham: Duke University Press.

Souza, Carlos R. 2014. "Orquestras e vitrolas no acompanhamento do espetáculo cinematográfico silencioso brasileiro: o caso do cinema Triângulo, um saco de pancadas exemplar". Rebeca 6(6): 1-29.

Souza, José I. M. 2004. Imagens do passado: São Paulo e Rio de janeiro nos primórdios do cinema. São Paulo: Editora Senac São Paulo. 


\section{FILMOGRAFIA}

As sete maravilhas do Rio de Janeiro [curta-metragem, 35mm] Dir. Humberto Mauro. Brasil Vita Film, Brasil, 1934.

Acabaram-se os otários [longa-metragem]. Dir. Luiz de Barros, Sincrocinex, Brasil, 1929.

Recebido em 08-08-2017. Aceite para publicação em 20-12-2017. 